\title{
Nationwide Evaluation of Potential Energy Savings and Payback of Integrated Building and Battery Energy Storage System through Model Predictive Controls
}

\author{
Hannah Fontenot ${ }^{1}$, Bing Dong ${ }^{1}$, Karen Aradillaz ${ }^{2}$, Gabriela Pineda ${ }^{2}$, Zhaoxuan Li $^{2}$, Tianhui Jiang ${ }^{2}$ \\ ${ }^{1}$ Department of Mechanical and Aerospace Engineering, Syracuse University, \\ Syracuse, New York, U.S.A. \\ ${ }^{2}$ Department of Mechanical Engineering, University of Texas at San Antonio, \\ San Antonio, Texas, U.S.A.
}

\begin{abstract}
Building-integrated microgrids (BIMGs) are rising in popularity due to their flexibility in incorporating multiple distributed energy resources including renewable energy sources and battery energy storage systems (BESS) and their natural suitability for demand response. To date, there have been almost no studies about the effect of various climate, building type, and electricity prices on BESS's potential for peak load reduction and energy cost savings. In this study, all sixteen U.S. Department of Energy (DOE) commercial reference building types are simulated with weather data from eighty U.S. cities across all eight ASHRAE climate zones using model predictive control (MPC) algorithm and incorporating BESS and varying electricity price schemes for Intelligent Building to Battery (B2B) control. Results show that cities in colder climate zones can expect up to $3 \%$ greater cost and demand savings than in hotter climate zones; additionally, cities with time-of-use price scheme can expect up to $60 \%$ shorter payback period than those with tiered prices.
\end{abstract}

\section{Introduction}

Buildings account for more than $40 \%$ of the total energy demand in the U.S., resulting in an annual national energy bill totalling more than $\$ 430$ billion according to a MultiYear Program Plan from the Building Technologies Office of the U.S. Department of Energy (2016) . With the increasing penetration of distributed energy resources such as photovoltaic (PV) systems, electric vehicles (EVs), and battery energy storage systems (BESS) at the individual building level, electrical load patterns become uncertain and variable, contributing to grid instability and energy waste. At the grid level, the introduction of renewable energy also makes the power system status more uncertain and variable, which requires more ancillary services to ensure system supply adequacy and reliability. Thus, the need for ancillary service provisions will increase substantially, and utility will require more flexible loads. A demand response program is one of the solutions; however, this is currently disconnected from the needs of building owners.

One potential solution that also directly serves the needs of building owners is using battery energy storage system. Whether or not a building is solar-powered, a BESS can help to smooth out power fluctuations in building demand or renewable generation. Batteries are beneficial to building operators because they provide them with the capability to purchase and store extra power during off- peak pricing time and use that power later during peak price times. This capability becomes especially effective if the building is also solar-powered. In this case, the BESS can store surplus solar energy during peak production times (i.e., during the day) and provide energy in the evening when prices are high and solar power generation is low. Thus the surplus solar energy need not be curtailed, and the building's peak grid demand is shaved. When used in this manner, battery energy storage can result in significant energy savings. The benefits of energy storage for solar-powered buildings are largely underestimated. This is mainly due to:

- The uncertainty in renewable energy production forecasting;

- The lack of integrated control of energy storage and flexible building loads.

The aim of this research is twofold. The first aim is to explore the potential of battery energy storage systems for increased energy efficiency in the most common commercial building types across all different climate zones in the U.S. The second is to explore the impact upon building-integrated BESS of differing utility rate structures. In this study, all sixteen Department of Energy (DOE) commercial reference building types are simulated with weather data from eighty U.S. cities across all eight ASHRAE climate zones using EnergyPlus, creating a baseline of energy usage. Then, an energy simulation is performed for each building in each city under a model predictive control (MPC) scheme using Matlab. Finally, Matlab is used to simulate the buildings' energy usage with integrated energy storage under multiple different electricity price rates and with five different levels of battery storage penetration. In total, 6400 simulation runs were conducted.

\section{Current State-of-the-Art}

The U.S. Department of Energy defines a microgrid as "a group of interconnected loads and distributed energy resources within clearly defined electrical boundaries that acts as a single controllable entity with respect to the grid" and which has the capability to "connect and disconnect from the grid to enable it to operate in both grid-connected or island-mode." (Office of Electricity Delivery and Energy Reliability, 2011) Building-integrated microgrids (BIMGs) are particularly beneficial to building operators due to their capability for demand side management (DSM), often used interchangeably with demand response 
(DR). DSM categorizes a broad array of actions which may be taken by the BIMG controller or building operator in response to supply side signals. These actions may include load shedding, load shifting, switching to more energy efficient appliances, increasing renewable energy penetration, and others. One of the most effective techniques for implementing DSM is to use battery energy storage. BESS can be combined with many other DR techniques (for example, peak shaving, load shifting, and renewable energy implementation) to amplify the cost- and energy-saving effects. One widely adopted approach for BIMG control is model predictive control (MPC). MPC uses knowledge of a system's current state to predict its future state and find the optimal control actions $\{u(k), \ldots, u(k+N-1)\}$ over a prediction horizon $N$. The first control action $u(k)$ is implemented and the optimization problem is solved again over the next $N$ time steps. Because it optimizes the system over a prediction horizon and not simply the next control step, MPC has the advantage of taking into account the future state of the system and future disturbances when making control decisions for the current next step. It has the ability to anticipate future events and act on that foreknowledge in the present. Additionally, MPC problem has the advantage of being relatively easy to formulate, since all that is required is the system dynamic model.

Many researchers study the potential of DSM and DR techniques (both with and without BESS) in reducing building energy use and energy costs, as well as the performance of MPC algorithms in implementing such measures. O'Shaughnessy, Cutler, Ardani, and Margolis (2018) used the U.S. National Renewable Energy Laboratory's Renewable Energy Optimization (REopt) model to evaluate cost-optimal technology selection, sizing, and dispatch for residential BIMGs under several different rate structures. REopt solves a mixed-integer linear program to minimize life cycle energy costs for a BIMG by selecting the optimal configuration of PV, BESS, and smart appliances. O'Shaughnessy et al. performed case studies assuming flat rates, time of use (TOU) rates (including the Arizona "super peak" tariff), and demand charges. Nan, Zhou, and Li (2018) developed a DR scheduling model for a smart residential community microgrid which uses interruptible loads in combination with different price programs to minimize residents' energy cost and peak load while maintaining occupant comfort within acceptable bounds. They found through case studies that depending on the price program, DR allowed residents to reduce total energy consumption by up to $1.5 \%$ and to shave peak loads by up to $4 \%$.

Mirakhorli and Dong (2018) developed a novel load aggregation method in a community-scale microgrid including BESS and electric vehicles using behaviourdriven, price-based MPC. Case studies on benchmark feeders demonstrated savings of up to $22 \%$ in operational cost, with peak demand reduction of up to $17 \%$. Jin, Feng,
Liu, Marnay, and Spanos (2017) formulated microgrid optimal dispatch with demand response (MOD-DR), a multi-objective optimization based on a large-scale microgrid model with flexible loads and integrated renewable energy and energy storage and incorporating uncertainty in real-time electricity price and renewable energy generation. They employed an adaptive dispatch strategy similar to MPC which resulted in overall peak load reduction of $17.5 \%$ and $8.8 \%$ cost savings for a campus prototype. Shakeri et al. (2017) developed a novel system architecture and control algorithm for an intelligent home energy management system (HEMS) which incorporates energy storage to facilitate demand response of a residential PV-integrated microgrid. Using a new smart rule-based controller algorithm which uses BESS for peak shaving in conjunction with controllable loads, they demonstrated cost savings of up to $20 \%$ for a single residence over a typical summer day.

Nwulu and Xia (2017) and Tabar, Jirdehi, and Hemmati (2017) investigated various demand response strategies, both with and without energy storage, for multi-building microgrids using multi-objective optimization problems. Nwulu and Xia demonstrated up to $11 \%$ cost savings and Tabar et al. demonstrated significant energy reduction in case studies. Wei, Zhu, and Yu (2016) developed an MPC-based framework for integrating the operations of smart buildings with BESS and the energy scheduling of the power grid through proactive demand participation, allowing buildings to proactively communicate their energy consumptions needs to the grid rather than passively react to grid signals. Case studies demonstrated that the proactive DR scheme can save up to $20 \%$ in building operating cost. Many similar studies can be found in the literature demonstrating the effectiveness and potential for cost and energy savings provided by DR programs. (Khalid, Ahmadi, Savkin, and Agelidis, 2016; Sachs \& Sawodny, 2016; Aghajani, Shayanfar, \& Shayeghi, 2015; Safamehr \& Rahimi-Kian, 2015; Xue, Wang, Yan, \& Cui, 2015; Mazidi, Zakariazadeh, Jadid, \& Siano, 2014; Zakariazadeh, Jadid, \& Siano, 2014; Aghaei \& Alizadeh, 2013)

\section{Summary of Previous Studies}

To the best of the authors' knowledge, this study is the first work to perform large-scale energy simulations with integrated BESS using MPC algorithm. This study encompasses all sixteen U.S. Department of Energy commercial reference building types in nearly one hundred cities across all eight U.S. climate zones. The simulations incorporate several different electricity pricing schemes including fixed rate, tiered rate, time-ofuse (TOU) rates, demand rates, seasonal rates, and combinations of these. In addition, to the best of the authors' knowledge, this study is the first work to perform a large-scale payback analysis for commercial buildingintegrated BESS. The results of this research may help to build a business case for either integrating BESS into 
initial building design or retrofitting existing buildings for increased energy efficiency.

\section{Methodology}

The intelligent Building to Battery (B2B) control consists of three layers: Baseline Generation, MPC Building Control, and Building-Battery Integration. The Baseline Generation layer consists of EnergyPlus simulations using the 16 DOE commercial reference building models and typical meteorological year (TMY) data from 80 U.S. cities to generate baseline energy usage for each building in each city. The Baseline Generation layer also outputs building disturbances for one year.

The second layer, MPC Building Control, takes as input the baseline building energy usage and building disturbances generated by the first layer. They are put through an MPC algorithm which outputs an intelligently controlled building energy usage. The final layer takes as input the intelligent building energy usage, electricity prices from 70 utility companies serving the 80 cities, and 5 different BESS sizes. These inputs are run through a nonlinear battery optimization, and the final output is an optimal building-and-battery energy usage with set-points for the building temperature and battery state of charge. The B2B control process is depicted in Figure 1.

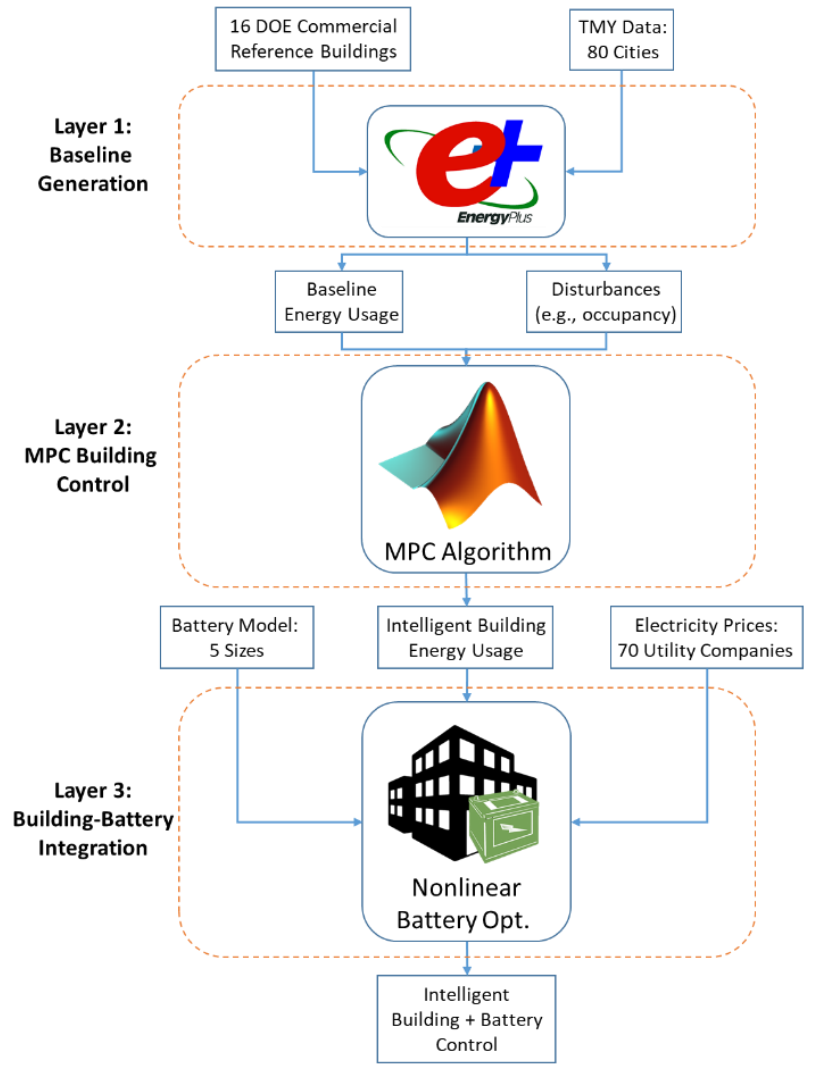

Figure 1: Intelligent B2B control scheme.

\section{Utility Price Dataset}

The utility prices used in this study are gathered from the individual tariffs of 70 electricity providers throughout the U.S. There are four main features to the utility price schemes: tiered rates, time-of-use (TOU) rates, seasonal rates, and demand charges. The first three features are energy charges (charged by kilowatt-hours); demand charges are charged by kilowatts. In a tiered rate scheme, the price per kilowatt-hour decreases as certain thresholds or tiers are reached. In a TOU rate scheme, the price per kilowatt-hour depends on the time of day; peak times are most expensive. A customer pays either tiered rates or TOU rates, but not both. If seasonal rates are in effect, the rates vary depending on the season; seasonal rates can apply to both tiered and TOU schemes. Finally, demand charges are charged based on billing demand, which is typically the highest kilowatt reading taken over a billing cycle. Demand charges may also apply to both tiered and TOU schemes. The Euler diagram in Figure 2 displays the possible pricing scheme combinations.

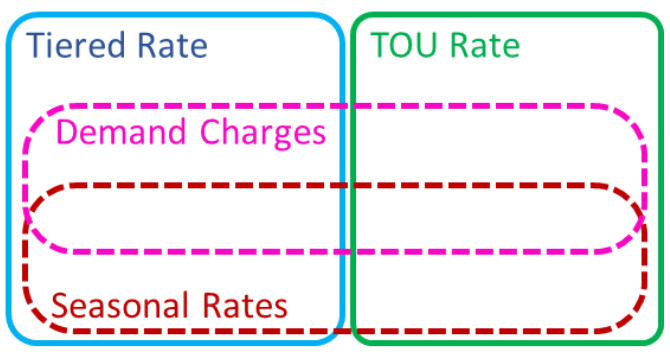

Figure 2: Pricing schemes.

\section{Building Model}

Well-established simulation tools, such as EnergyPlus (U.S. DOE, 2018), have demonstrated the potential to model commercial buildings where the fundamentals of heat transfer and thermal dynamics are accurately captured. The complexity and high number of model variables make these tools difficult to include in MPC unless co-simulation or other routines are used. Recently, researchers developed reduced order thermal network models to solve the individual building optimal control problem for MPC (Hazyuk, 2012). In this project, the authors have developed a further reduced order thermal resistance and capacitance (RC) network model which only has one temperature state, namely, space temperature $T_{\text {zone }}$, as depicted in Figure 3 below.

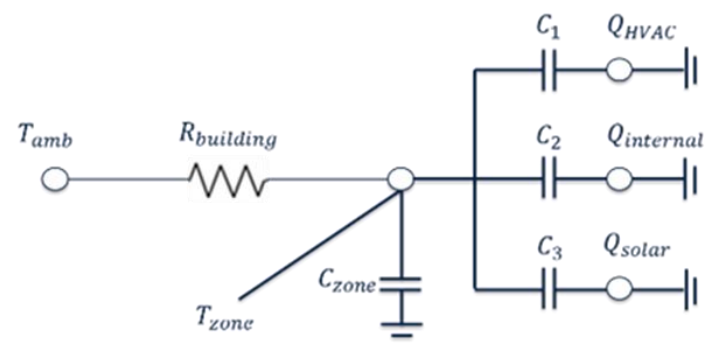

Figure 3: 1R3C building thermal model.

From the figure, the temperature state, $T_{z o n e}$, of the "super-zone" is given by:

$$
\begin{aligned}
C_{\text {zone }} \dot{T}_{\text {zone }}= & \frac{T_{\text {amb }}-T_{\text {zone }}}{R_{\text {building }}}+C_{1} Q_{H V A C} \\
& +C_{2} Q_{\text {internal }}+C_{3} Q_{\text {solar }}
\end{aligned}
$$

where $C_{\text {zone }}$ is the thermal capacitance of the super-zone (Joules per Kelvin); $C_{1}, C_{2}$, and $C_{3}$ are adjusted thermal capacitance parameters of the building envelope (Joules 
per Watt); $R_{\text {building }}$ is the average thermal resistance (Kelvin per Watt); $T_{a m b}, Q_{\text {internal }}$, and $Q_{\text {solar }}$ are the building disturbances (outdoor ambient temperature in Kelvin, internal heat gains due to occupants in Watts, and external heat gains due to solar radiation in Watts); and $Q_{H V A C}$ is the control input (HVAC cooling load in Watts). Hence, the dynamics of building in state-space format can be written as:

$$
\dot{x}=A_{x} x+B_{u_{x}} u_{x}+B_{w_{x}} w_{x}
$$

The system description (2) represents a linear, timeinvariant dynamical system.

To get the building accurate model parameters, we conducted parameter estimation based on simulation results of EnergyPlus models through temperature minimization:

$$
\begin{gathered}
\min \sum_{i=1}^{n}\left(x_{i}-T_{i}\right)^{2} \\
\text { s.to } \dot{x}=A_{x} x+B_{u_{x}} u_{x}+B_{w_{x}} w_{x}
\end{gathered}
$$

\section{Battery Model}

In this project, a nonlinear battery model based on equivalent circuit representation of the battery system can be expressed as

$$
P_{\text {batt }}(t)=N_{\text {cell }}\left(V_{\text {cell }}(t)-R_{\text {cell }}(t) \cdot I(t)\right) \cdot I(t)
$$

where $P_{\text {batt }}$ is the battery charging and discharging power, $N_{\text {cell }}$ is the number of the battery cells (assumed to be 100), $V_{\text {cell }}$ is the battery open circuit voltage, $R_{\text {cell }}$ is the battery resistance, and $I$ is the battery current.

The battery open circuit voltage is the difference of the electrical potential between the two terminals of a battery, when there is no external load connected. As the value of battery open circuit voltage is strongly dependent on battery SOC (State of Charge), it can be formulated as

$$
\begin{aligned}
V_{\text {cell }}(t)=V_{0} & +\frac{K}{1-\operatorname{SOC}(t)}+A e^{B \cdot \operatorname{SOC}(t)} \\
& +C \cdot \operatorname{SOC}(t)+D \cdot \operatorname{SOC}(t)^{2}
\end{aligned}
$$

where $V_{\text {cell }}$ is the battery cell voltage, $V_{0}$ is a base voltage, $K, A, B, C, D$ are the parameters which need to be fitted for each individual battery cell, and $S O C$ is the state of charge of the battery. The battery resistance can also be expressed based on $S O C$ as

$$
R_{\text {cell }}(t)=E+F \cdot \operatorname{SOC}(t)+G \cdot \operatorname{SOC}(t)^{2}
$$

where $E, F$, and $G$ are also the parameters which need to be fitted for each individual battery cell.

The battery SOC is calculated as follows:

$$
Q_{0} \frac{d}{d t} \operatorname{SOC}(t)=\left\{\begin{array}{l}
-\eta_{d} I_{d}(t) \\
-\eta_{c} I_{c}(t)
\end{array} \text { for } I_{d}(t)>0\right.
$$

where $Q_{0}$ is the nominal battery capacity, $\eta_{d}$ is discharging efficiency, $\eta_{c}$ is the charging efficiency, $I_{d}$ is the discharging current, and $I_{c}$ is the charging current. By redefining the battery current in (7), it can be rewritten as

$$
Q_{0} \frac{d}{d t} \operatorname{SOC}(t)=\eta_{c} I(t)-\eta_{d} I(t)
$$

where $I(t)=I_{d}(t)-I_{c}(t), I_{d}(t) \cdot I_{c}(t)=0 \quad$ (since charging and discharging cannot occur simultaneously), $I_{d}(t) \geq 0$, and $I_{c}(t) \geq 0$.

\section{Model Predictive Control}

In this study, we use model predictive control to intelligently control the building energy usage before incorporating the battery energy storage (layer 2 of the $\mathrm{B} 2 \mathrm{~B}$ control scheme). MPC is formulated as follows, as per Camacho and Bordons (2004):

$$
\begin{array}{lc}
\min _{\{u(k)\}} \quad \sum_{i=0}^{N-1} J(x(k+i), u(k+i)) \\
\text { s.to } \quad x(i+1)=A x(i)+B_{u} u(i)+B_{w} w(i) \\
\{u(k)\}=\{u(k), \ldots, u(k+N-1)\} \\
x(0)=x(k) \\
x(i) \in X \\
u(i) \in \mathcal{U}, \quad \forall i \in \mathbb{Z}_{0}^{N-1}
\end{array}
$$

where $J(x(k+i), u(k+i))$ is a cost function. In this case, $J$ is the total energy cost. Here the control actions $\{u(k)\}$ are $Q_{H V A C}(k)$.

\section{Sizing of Battery Energy Storage System}

For each of five battery factors, the capacity of the BESS is sized according to the following equation:

$$
\operatorname{cap}_{\text {batt }}=\frac{F_{\text {batt }} \cdot \max \left(E_{\text {base }}\right) \cdot 1000 \mathrm{~W} / \mathrm{kW}}{N_{\text {cell }}}
$$

where $F_{\text {batt }}$ is the battery factor $(10,20,30,40$, or $50 \%$ in the case of this study), $E_{\text {base }}$ is the annual baseline energy use in kilowatt-hours, and $N_{\text {cell }}$ is the number of cells in the BESS. cap batt is the BESS's energy capacity in kilowatt-hours. The battery systems are sized according to the maximum kilowatt-hour value of the baseline energy usage $E_{\text {base }}$.

\section{Results and Discussion}

We discuss two key results: demand cost reduction and simple payback period for BESS. These results are compared by climate zone, price structure, and building.

\section{Selection of Cities}

This study analyses potential energy savings and peak demand reduction for buildings in 80 cities spanning all 8 ASHRAE climate zones found in the U.S. Figure 4 displays the number of cities studied per climate zone, as well as the relative temperature of each zone, from very hot (zone 1) to subarctic (zone 8).

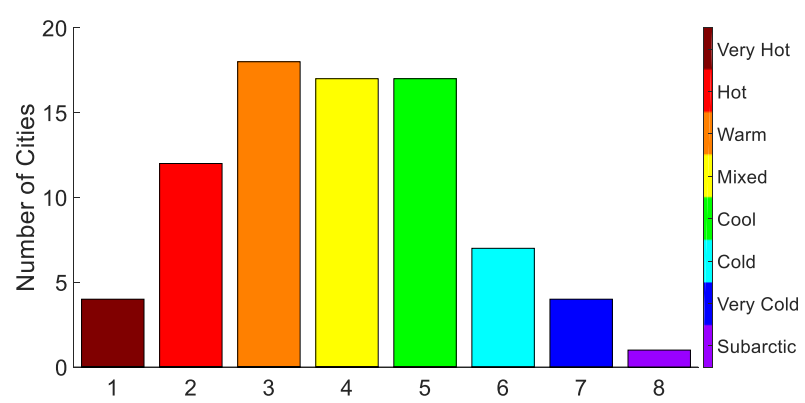

Figure 4: Number of cities studied in each climate zone. 
The cities were selected to reflect relative regional population density. Additionally, only cities for which TMY and electricity rate data could be found were selected. Zone 1, which includes the southernmost tip of Florida and all of Hawaii, and zone 8, which encompasses approximately two-thirds of Alaska, serve to demonstrate the relative density-driven city selection process.

\section{Total Energy Cost Reduction by Climate Zone}

First we examine the reduction in total energy cost. Table 1 shows the mean absolute energy cost reduction per simulation run, by climate zone. Figure 5 shows the percent reduction in total energy costs across all 80 cities, grouped by climate zone.

Table 1: Mean absolute energy cost reductions.

\begin{tabular}{|c|c|c|c|}
\hline Zone & Reduction (\$1000) & Zone & Reduction (\$1000) \\
\hline 1 & 319.61 & 5 & 350.97 \\
\hline 2 & 339.80 & 6 & 336.73 \\
\hline 3 & 347.51 & 7 & 319.61 \\
\hline 4 & 350.97 & 8 & 409.02 \\
\hline
\end{tabular}

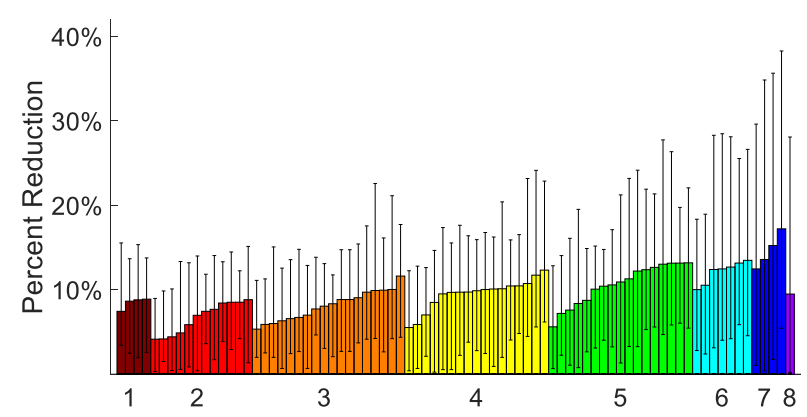

Figure 5: Total energy cost reduction by climate zone.

Each bar represents one city. Bar height is the average percent reduction in demand cost over all 16 building types in the city and over all 5 battery sizes (i.e., 80 simulations per city). Error bars show the maximum and minimum percent reduction.

It is interesting to note that there is a general upward trend in total energy cost reduction as the climate gets colder. This may be explained by the fact that buildings in colder climates require more heating than cooling annually. In EnergyPlus simulations, the majority of heating energy is derived from natural gas, whereas the entirety of cooling energy is obtained from electricity use. This results in baseline electricity use levels which are lower in colder climates than in hotter climates. Therefore when B2B control is applied and energy use is reduced, the percent reduction is often greater even if the absolute reduction may not be.

\section{Demand Cost Reduction by Climate Zone}

The first key result is the reduction in demand cost. Figure 6 shows this percent reduction across all 80 cities, grouped by climate zone.

As before, each bar represents the average percent reduction for one city, with error bars showing the maximum and minimum reductions over all simulations for that city. Blank spaces in the figure (i.e., zero percent reduction) indicate that the city does not have a demand

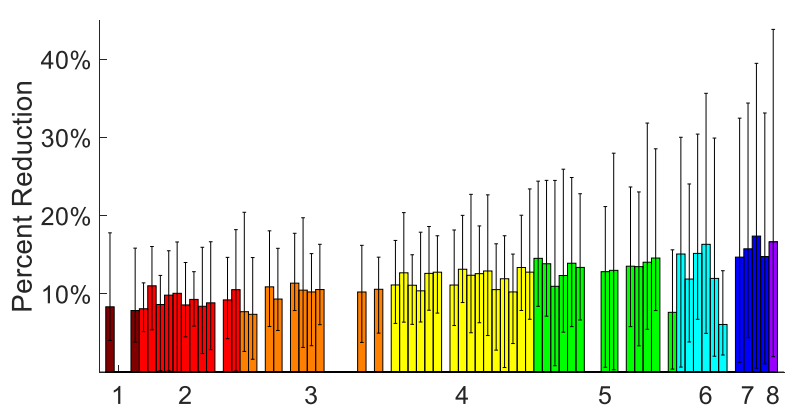

Figure 6: Demand cost reduction by climate zone.

charge, not that the city experienced zero reduction in billing demand. On average, demand cost constitutes approximately one percent of total energy cost.

For all cities where customers pay demand charges, the reduction in demand cost is significant, averaging from $5 \%$ to $17 \%$, with maximum reduction values up to $42 \%$. Similarly to the total energy cost reduction, the demand cost reduction also shows an upward trend from hot to cold climates. This trend can be explained in the same way as the trend in Figure 5.

\section{Demand Cost Reduction by Price Structure and Building}

Also of interest is the way that expected demand cost reduction is affected by building type and pricing structure. Figure 7 displays the demand cost reduction by building for Wilmington, a city with tiered electricity rates, and Charleston, a city with TOU electricity rates. Both cities experience seasonal demand rates.
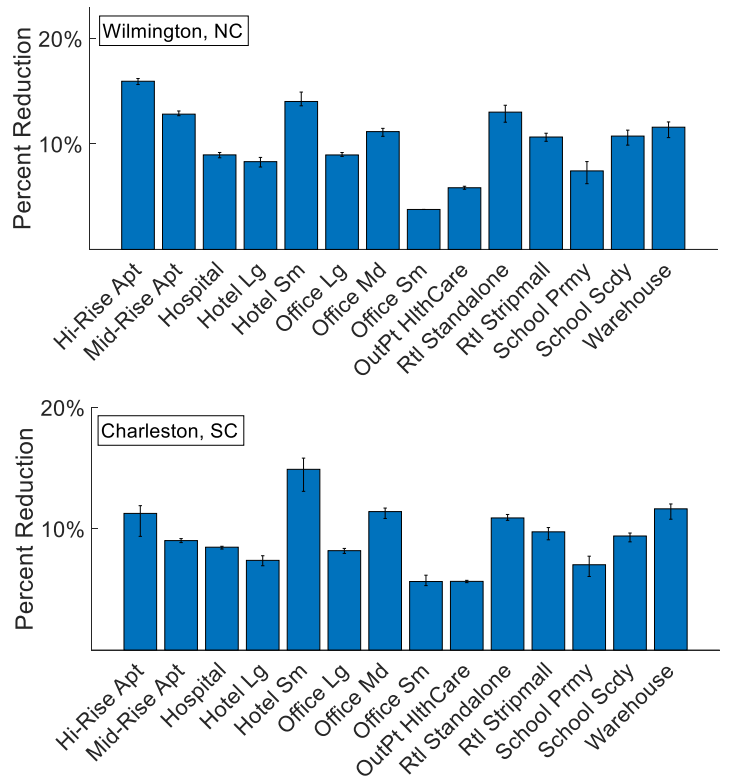

Figure 7: Demand cost reduction by building - tiered rates (top) and TOU rates (bottom).

Both cities are located within climate zone 3 , with a hot and humid climate; both have a seasonal demand cost. Each bar represents one of the DOE commercial reference buildings. Bar height is the average percent reduction across all five battery sizes. Error bars show the maximum and minimum percent reduction for each building. The building types are, from left to right: high-rise apartment 
building, mid-rise apartment building, hospital, large hotel, small hotel, large office, medium office, small office, outpatient healthcare facility, standalone retail center, retail strip mall, primary school, secondary school, and warehouse.

As the figure shows, there is little variation in demand cost reduction across different battery factors for the same building, but there is significant variation in demand cost reduction across different buildings. In Wilmington, the three buildings with the greatest demand cost reduction are high-rise apartment, small hotel, and standalone retail. In Charleston, these same three building types are within the top five with greatest demand cost reduction. The apartment building is a multi-family residence; as such, it can be expected to experience peak load during peak pricing times (for TOU). Similar reasoning can be applied to a small hotel. Thus the incorporation of BESS will provide the greatest percentage reduction in demand and therefore demand cost for these particular buildings, especially under TOU price scheme.

It is worth nothing that the average percent reduction is greater for Wilmington (tiered prices) than in Charleston (TOU prices), a reminder that the conclusions drawn from Figures 5 and 6 are not universally true, but should serve more as a general guideline when forming initial estimates regarding the potential benefits of BESS for a particular building or city.

\section{Simple Payback Period by Price Structure and Climate Zone}

An important consideration for building owners when sizing and purchasing a BESS is payback period. Simple payback may be calculated as follows (Akter, Mahmud, \& Oo, 2017):

$$
\frac{F_{\text {batt }} \cdot \max \left(E_{\text {base }}\right) \cdot C_{\text {batt }}}{C_{\text {base }}-C_{B 2 B}}
$$

where $C_{\text {batt }}$ is the cost of the battery in dollars per kilowatt-hour of rated capacity, $E_{\text {base }}$ is the annual baseline energy use in kilowatt-hours, and $C_{b a s e}$ and $C_{B 2 B}$ are the total annual energy costs for baseline use and using B2B control, respectively. In words, the simple payback period (in years) is equal to the total cost of the BESS (in dollars) divided by the total annual cost reduction (in dollars per year). For this study, a cost of $\$ 290$ per kWh of capacity was assumed, as in (McLaren, Andersen, Laws, Gagnon, DiOrio, \& Li, 2018). This cost represents the total installed cost of storage, including hardware, engineering, labor, and operation and maintenance, assuming a twenty-year battery lifetime. This is comparable to current commercial-use BESS prices.

The total cost of BESS and therefore simple payback period increases with the battery factor. The cost increases linearly, whereas the payback period may not. Therefore a building operator's objective in sizing a BESS is to maximize the battery capacity and minimize the payback period simultaneously. Figure 8 depicts this trade-off for Wilmington (tiered prices) and Charleston (TOU prices), both of which are located within climate zone 3 . In the figure, each point on the plot is an average value over all 16 building types.

As can be seen in the figure, the costs of BESS for both cities are similar, ranging from about $\$ 2000$ to about $\$ 14$ 000. However, the simple payback period differs somewhat between the two cities. Building operators in Wilmington can expect an average simple payback period between 0.5 and 1 year, while their counterparts in Charleston can expect an average payback period of up to 2 years. This implies that building operators who pay tiered electricity rates can expect to benefit slightly more quickly from investing in a BESS.

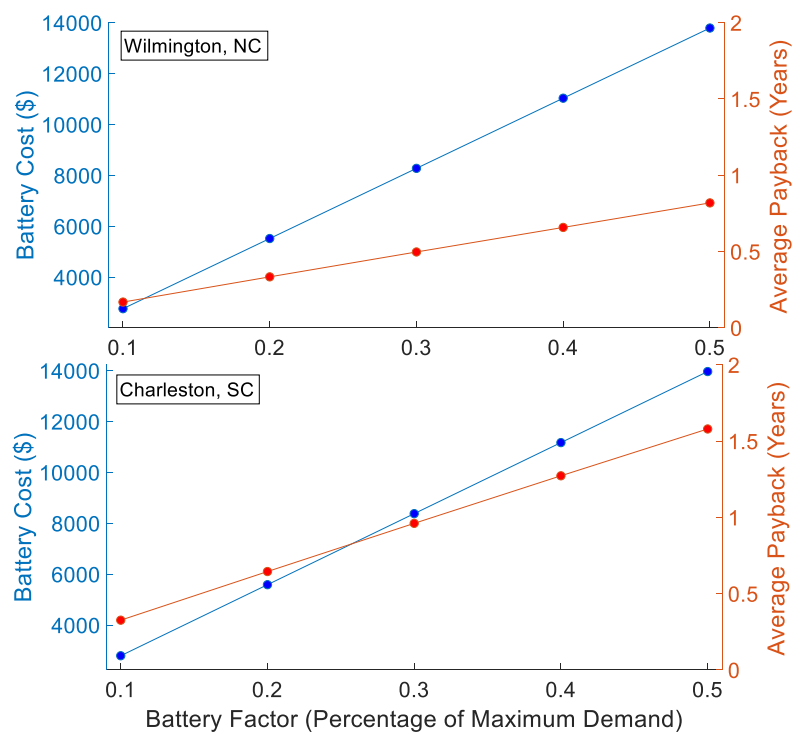

Figure 8: Simple payback for city with tiered rates (top) and TOU rates (bottom).

The optimal payback period can be defined as the point where the two curves intersect after being normalized to fall within zero and one. Because the battery factors and hence the average payback years are discrete values, the optimal payback value can be interpreted as that value where the normalized values of battery cost and average payback period are closest to each other. In the case of the two cities in Figure 8, the optimal payback for Wilmington is 0.75 years (at a battery factor of $50 \%$ ) and the optimal payback for Charleston is approximately 1.5 years (also at a battery factor of 50\%). Figure 9 compiles all of the average optimal values for simple payback period for all cities. Diamonds containing black circles indicate a city with TOU pricing.

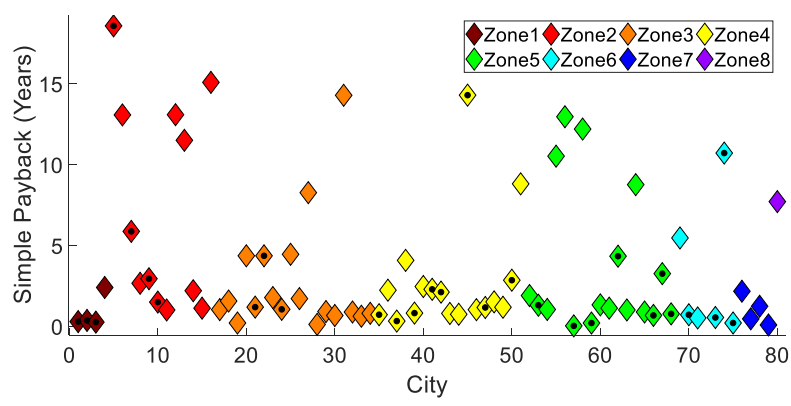

Figure 9: Optimal average payback period by city. 
As can be seen in the figure, the vast majority of cities (69 out of the 80) display an optimal average payback period of under ten years. Out of the eleven cities with optimal values greater than ten years, only three are cities with TOU pricing - one each in climate zones 2,4 , and 6 . This supports the conclusion from Figure 8, that cities with TOU pricing can expect better average payback periods than those with tiered rates, in general. The general spread of the plot also indicates that climate does not have a significant impact on the optimal payback period, although a very slight general downward trend can be observed in the plot as the climate goes from hot to cold.

\section{Simple Payback Period by Price Structure and Building}

Figure 10 displays the simple payback period by building for Wilmington (tiered rates) and Charleston (TOU rates), both located within climate zone 3 . Each point represents a single simulation run; therefore there are five points for each building representing the five battery factors.

In Wilmington, all buildings can expect average BESS payback periods of under two years for any size BESS. In Charleston, all building types can expect payback periods of under four years for any size BESS. The small office and strip mall retail center can expect payback periods of up to three years with the largest sized BESS. While it is outside the scope of this work, it is reasonable to expect that using a larger BESS size would further decrease the expected payback period. However, as that would also increase the total cost of the BESS, further analysis would be required to determine the best course of action for those building types in a TOU rate scheme. This result is to be expected, given the spread of optimal values in Figure 9.

\section{Conclusion}

This study has investigated the savings potential of building-integrated battery energy storage systems for 80 cities across the US, within 8 ASHRAE climate zones ranging from very hot to subarctic, for all $16 \mathrm{DOE}$ commercial reference building types, for multiple different electricity price schema, and for a wide array of relative battery sizes ranging from 10 to 50 percent of peak energy usage. We found that there is a huge potential for savings, up to $45 \%$ demand cost reduction (mean value of $12 \%$ ) and up to $40 \%$ total cost reduction (mean value of $10 \%$ ), depending on the climate, electricity rates, and building type.

In general, cities in colder climates can expect greater reductions in terms of percentage of baseline values, although not necessarily for absolute reductions. Additionally, building operators who pay time-of-use rates for electricity may expect a much greater percentage reduction in demand cost and a much shorter BESS payback period than those who pay tiered electricity rates. The potential for cost savings is greatest for building operators who pay demand charges, as BESS is especially suited for peak-shaving and reducing billing demand.
Future extensions of this work will include integrated model predictive control of buildings and battery, more extensive and detailed electricity price application, and integration of PVs.

\section{Acknowledgement}

This research is supported by the National Science Foundation (NSF) titled: Collaborative Research: Empowering Smart Energy Communities: Connecting Buildings, People, and Power Grids, Award Number: 1637249 and CPS Energy of San Antonio.

\section{References}

Aghaei, J. and Alizadeh, M.I. (2013). Multi-objective self-scheduling of CHP (combined heat and power)based microgrids considering demand response programs and ESSs (energy storage systems). Energy $55,1044-1054$.

Aghajani, G.R., Shayanfar, H.A., and Shayeghi, H. (2015). Presenting a multi-objective generation scheduling model for pricing demand response rate in micro-grid energy management. Energy Conversion and Management 106, 308-321.

Akter, M.N., Mahmud, M.A., and Oo, A.M.T. (2017). Comprehensive economic evaluations of a residential building with solar photovoltaic and battery energy storage systems: An Australian case study. Energy and Buildings 138, 332-346.

Building Technologies Office, U.S. Department of Energy (2016). Building Technologies Office MultiYear Program Plan: Fiscal Years 2016-2020.

Camacho, E.F. and Bordons, C. (2004). Model Predictive Control. Springer-Verlag. London (UK).

Hazyuk, I., Ghiaus, C., and Penhouet, D. (2012). Optimal temperature control of intermittently heated buildings using Model Predictive Control: Part I - Building modelling. Building and Environment 51, 379-387.

Jin, M., Feng, W., Liu, P., Marnay, C., and Spanos, C. (2017). MOD-DR: Microgrid optimal dispatch with demand response. Applied Energy 187, 758-776.

Khalid, M., Ahmadi, A., Savkin, A.V., and Agelidis, V.G. (2016). Minimizing the energy cost for microgrids integrated with renewable energy resources and conventional generation using controlled battery energy storage. Renewable Energy 97, 646-655.

Mazidi, M., Zakariazadeh, A., Jadid, S., and Siano, P. (2014). Integrated scheduling of renewable generation and demand response programs in a microgrid. Energy Conversion and Management 86, 1118-1127.

McLaren, J., Andersen, K., Laws, N., Gagnon, P., DiOrio, N., and Li, X. (2018). Identifying critical factors in the cost-effectiveness of solar and battery storage in commercial buildings.

Mirakhorli, A. and Dong, B. (2018). Model predictive control for building loads connected with a residential distribution grid. Applied Energy 230, 627-642. 
Nan, S., Zhou, M., and Li, G. (2018). Optimal residential community demand response scheduling in smart grid. Applied Energy 210, 1280-1289.

Nwulu, N. and Xia, X. (2017). Optimal dispatch for a microgrid incorporating renewables and demand response. Renewable Energy 101, 16-28.

Office of Electricity Delivery and Energy Reliability, U.S. Department of Energy (2011). DOE Microgrid Workshop Report.

O'Shaughnessy, E., Cutler, D., Ardani, K., and Margolis, R. (2018). Solar plus: Optimization of distributed solar PV through battery storage and dispatchable load in residential buildings. Applied Energy 213, 11-21.

Sachs, J. and Sawodny, O. (2016). A two-stage model predictive control strategy for economic diesel-PVbattery island microgrid operation in rural areas. IEEE Transactions on Sustainable Energy 7, 903-913.

Safamehr, H. and Rahimi-Kian, A. (2015). A costefficient and reliable energy management of a microgrid using intelligent demand-response program. Energy 91, 283-293.
Shakeri, M. et al. (2017). An intelligent system architecture in home energy management systems (HEMS) for efficient demand response in smart grid. Energy and Buildings 138, 154-164.

Tabar, V.S., Jirdehi, M.A., and Hemmati, R. (2017). Energy management in microgrid based on the multi objective stochastic programming incorporating portable renewable energy resource as demand response option. Energy 118, 827-839.

U.S. Department of Energy (2018). EnergyPlus ${ }^{\mathrm{TM}}$ Version 9.0.1 Documentation: Getting Started.

Wei, T., Zhu, Q., and Yu, N. (2016). Proactive demand participation of smart buildings in smart grid. IEEE Transactions on Computers 65(5), 1392-1406.

Xue, X., Wang, S., Yan, C., and Cui, B. (2015). A fast chiller power demand response control strategy for buildings connected to smart grid. Applied Energy 137, 77-87.

Zakariazadeh, A., Jadid, S., and Siano, P. (2014). Smart microgrid energy and reserve scheduling with demand response using stochastic optimization. Electrical Power and Energy Systems 63, 523-533.
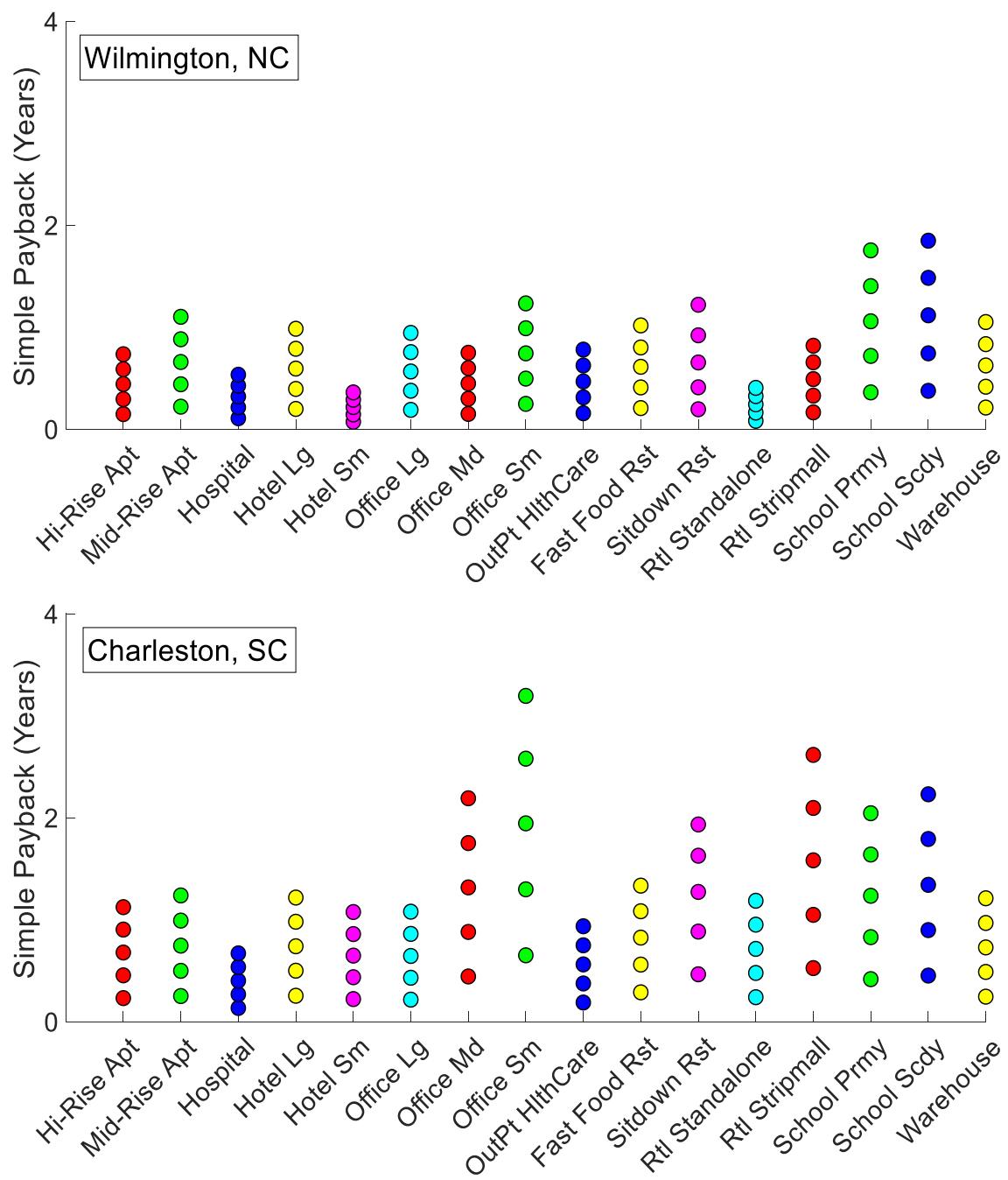

Figure 10: Simple payback by building - tiered rates (top) and TOU rates (bottom). 